\title{
Erratum to: One Intraoperative Dose of Tranexamic Acid for Patients Having Primary Hip or Knee Arthroplasty
}

\author{
Fiona E. Ralley BSc, MBChB, FRCA, FRCSC, \\ Donna Berta RN, Valerie Binns RN, James Howard MD, MSc, FRCSC, \\ Douglas D. R. Naudie MD, FRCSC
}

Published online: 9 March 2010

(C) The Association of Bone and Joint Surgeons (B) 2010

\section{Erratum to: Clin Orthop Relat Res DOI 10.1007/s11999-009-1217-8}

It has been brought to our attention by one of the online readers that there is an error in the Abstract and Results sections of our manuscript. We meant to say that the decrease in hemoglobin was less in 2008 than in 2007-as shown by the data in Table 2 and hence indicating, as the Discussion correctly points out, that the TEA protocol seems to reduce the perioperative decrease in hemoglobin when compared with a similar cohort of patients who did not receive TEA.

The first sentence in the Results section of the Abstract currently states: We found a reduction in the decrease in hemoglobin in 2007 compared with 2008 for THA and TKA (46 to $39 \mathrm{~g} / \mathrm{L}$ and 45 to $36 \mathrm{~g} / \mathrm{L}$, respectively), which led to a reduction in transfusion rates $(13.5 \%$ to $3.6 \%$ and

(Ralley FE, Berta D, Binns V, Howard J, Naudie DDR. One intraoperative dose of tranexamic acid for patients having primary hip or knee arthroplasty. Clin Orthop Relat Res. 2009 Jan 9. [Epub ahead of print]).

The online version of the original article can be found under doi:10.1007/s11999-009-1217-8.

\section{F. E. Ralley}

Department of Anesthesia and Perioperative Medicine,

University of Western Ontario, London, ON, Canada

D. Berta, V. Binns

Ontario Transfusion Coordinators (ONTraC), London, ON,

Canada

\section{J. Howard, D. D. R. Naudie ( $\square)$}

Division of Orthopaedic Surgery, London Health Sciences

Center, University Hospital, 339 Windermere Road, London,

ON N6A 5A5, Canada

e-mail: Douglas.Naudie@lhsc.on.ca
$13.1 \%$ to $2.0 \%$, respectively and higher hemoglobin levels at discharge.

The first sentence in the Results section of the Abstract should be: We found a reduction in the decrease in hemoglobin in 2008 compared with 2007 for THA and TKA (39 from $46 \mathrm{~g} / \mathrm{L}$ and 36 from $45 \mathrm{~g} / \mathrm{L}$, respectively), which led to a reduction in transfusion rates $(3.6 \%$ from $13.5 \%$ and $2.0 \%$ from $13.4 \%$, respectively) and higher hemoglobin levels at discharge.

The first sentence in the Results section of the manuscript currently states: The decrease in hemoglobin was less in 2007 than in 2008 for patients who had THAs and TKAs (46 to $39 \mathrm{~g} / \mathrm{L}[\mathrm{p}<0.001]$ and 45 to $36 \mathrm{~g} / \mathrm{L}$ [p $<0.001$ ] respectively) (Table 2 ).

The first sentence in the Results section of the manuscript should be: The decrease in hemoglobin was less in 2008 than in 2007 for patients who had THAs and TKAs (39 from $46 \mathrm{~g} / \mathrm{L}[\mathrm{p}<0.001]$ and 36 from $45 \mathrm{~g} / \mathrm{L}$ [p $<0.001$ ], respectively) (Table 2).

We apologize for this error. 